\title{
Analysis of dynamic characteristics of climbing formwork under wind loads
}

\author{
Hu Shicheng ${ }^{1,2}$, Li Jun ${ }^{1,2}$ \\ ${ }^{1}$ College of Mechanical and Electrical Engineering of Central South University, Changsha 410000, China \\ ${ }^{2}$ State Key Laboratory of high performance complex manufacturing, Changsha 410000, China
}

\begin{abstract}
This article took the climbing formwork which constructed on the bridge at a height of 100 meters as the prototype, then established the finite element model and conducted modal analysis. The APDL language is used to load the wind load which is simulated by the Matlab programming then calculated the displacement and acceleration responses of the climbing formwork and further. The results show that the bending effect of the climbing formwork is more obvious. This calculation method of calculating the wind load, improve the anti-wind design method of the climbing formwork.
\end{abstract}

\section{Introduction}

With the development of urbanization in China, which tall buildings have become mainstream, bridge construction continuous developed to the direction of the large span and high piers, and construction is becoming more and more difficult. Climbing formwork has the advantages of fast, light, low construction cost, and also can use the concrete which have shaped to self-climbing, that has been widely used in the construction of cable towers, high pier and other high-rise structures ${ }^{[1-3]}$.

With the increasing of the construction height, which the climbing formwork is more and more sensitive to wind, so wind load must be considered in the design of hydraulic climbing formwork. In the field of hydraulic climbing formwork researching, there is a lack of relatively accurate and simple design specification which in the calculation of wind load. There is a great deal of experience and blindness that use the wind vibration coefficient given by the code to calculate the wind load. This paper are studied the wind vibration response, which obtained the frequency characteristics of the hydraulic climbing formwork. It is a good foundation for wind vibration coefficient and fatigue damage of the next step, It provides reference basis for the engineering design of climbing formwork.

\section{Dynamic characteristic analysis}

\subsection{Finite element modeling}

Building the formwork finite element model with Hypermesh which is a kind of finite element software. Because the structure of climbing formwork is slender bar.so beam element for main members (Beam188)and link element for the screw assembly(link8).The 3D diagram of the hydraulic clamshell frame is shown in figure 1.The specific finite element modeling parameters of crawling mode are shown in table 1 .

\subsection{Modal analysis of climbing formwork}

To study the dynamic response of the climbing formwork, need understand the dynamics of the climbing structure. Based on the established finite element model, the Block Lanczos algorithm is used for modal analysis, which obtained the natural frequency and model diagram. The top 4 order vibration mode diagrams as shown in figure 2 to figure 5 , the first 10 order frequency are shown in table 3 . The first two order mode diagrams show that the torsional vibration along the z-axis of the second floor platform. The third-order mode diagram is shown as the translation of the upper two platforms along the x-axis. The fourth mode diagram shows the translation of the next two platforms along the x-axis. Table 2 shows that the frequency of the front 10 of the crawling die does not exceed 5 .

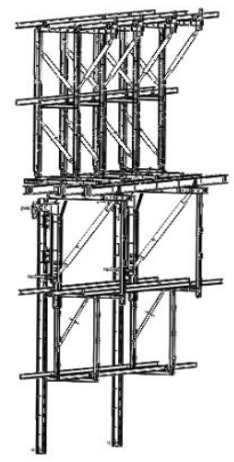

Fig. 1. 3d model of hydraulic climbing formwork 
Table 1. Finite element modeling parameters

\begin{tabular}{|c|c|}
\hline Parameter & Data \\
\hline Material & Q235B \\
\hline Elasticity modulus & $2.03 \times 10^{5} \mathrm{~N} / \mathrm{mm}$ \\
\hline Poisson's ratio & 0.3 \\
\hline Yield strength & $235 \mathrm{Mpa}$ \\
\hline Density & $7.85 \times 10^{3} \mathrm{~kg} / \mathrm{m}^{3}$ \\
\hline
\end{tabular}

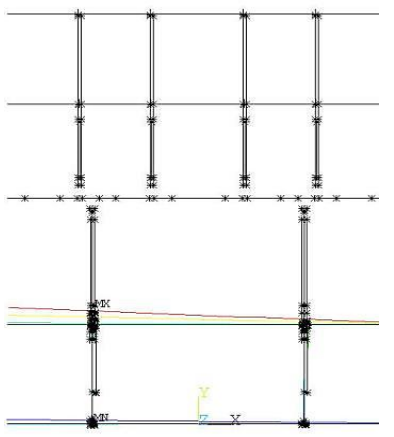

Fig.2. First mode diagram

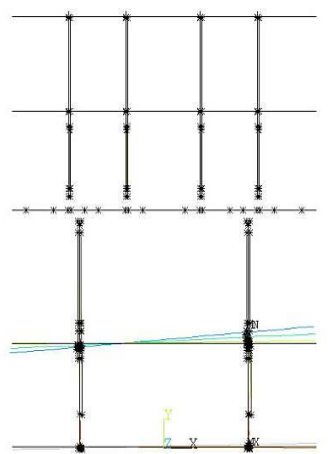

Fig.3. Second mode diagram

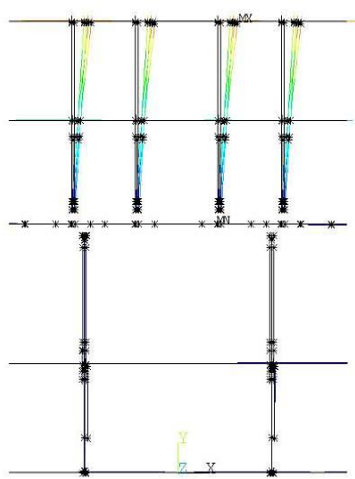

Fig.4. Third mode diagram

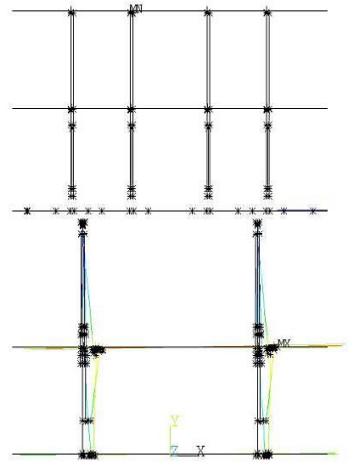

Fig.5. Fourth mode diagram
Table 2. Top 10 frequencies of climbing formwork

\begin{tabular}{|c|c|c|c|c|c|}
\hline Order number & 1 & 2 & 3 & 4 & 5 \\
\hline frequency (HZ) & 0.557 & 1.212 & 2.166 & 2.450 & 3.047 \\
\hline Order number & 6 & 7 & 8 & 9 & 10 \\
\hline frequency (HZ) & 3.1 & 3.512 & 4.138 & 4.266 & 4.499 \\
\hline
\end{tabular}

\section{Wind vibration response}

\subsection{Simulated wind velocity}

To get the wind response in the time zone, Firstly, decomposing the spectral density function of wind load into a time function. Then, disserting structure in the finite element software. Last, loading wind load that is obtained by load simulation to the corresponding element nodes of formwork model. The response of the structure is obtained by directly solving the differential equation of motion in the time domain ${ }^{[4]}$.

The current method of stochastic process simulation, It can be divide into four kinds: Harmonic superposition method, linear filter method, inverse Fourier transform method and wavelet analysis ${ }^{[5]} \cdot$ In this paper, the harmonic synthesis method is used to simulate the wind speed time history at high altitude.

The principle of harmonic synthesis is, using a series of cosine function sequence with random frequency to simulate the fluctuating wind, which consider the wind speed spectrum of formwork. ${ }^{[6]}$ For points with different coordinates $(1,2,3, \ldots ., m)$, formula is a spectral density function matrix of the wind speed $V_{j}(t)(j=1,2, \ldots, m)^{[7]}$ :

$$
\mathrm{s}(\omega)=\left[\begin{array}{ccc}
S_{11}(\omega) & \cdots & S_{1 m}(\omega) \\
\vdots & \ddots & \vdots \\
S_{m 1}(\omega) & \cdots & S_{m m}(\omega)
\end{array}\right]
$$

In formula (1), $S_{i i}(\omega)$ is the auto-spectral density; $S_{i j}(\omega)(i \neq j)$ is the cross-power spectral density, which is generally the complex number:

$$
S_{\mathrm{ij}}(\omega)=\sqrt{S_{\mathrm{ii}}(\omega) S_{\mathrm{jj}}(\omega)} * \operatorname{ch}(\mathrm{f}) * e^{i \varnothing(\omega)}
$$

In formula (2), $\varnothing(\omega)$ is the phase angle of he cross-power spectral.ch(f) is the function of frequency and distance between two points, formula following:

$$
\operatorname{ch}(\mathrm{f})=\exp \left(-\frac{C_{z} * f * \Delta z}{v}\right)
$$

In formula (3), $C_{z}$ is the attenuation coefficient, $\Delta \mathrm{z}$ is the vertical space, $V$ is the average wind speed. (1).

Cholesky decomposition was applied to the formula

$$
\mathrm{S}(\omega)=\mathrm{H}(\omega) * H(\omega)^{T}
$$

Because the fluctuating wind can be considered as Gaussian process and stationary random process according to the wind records.so formula(4) is the fluctuating wind velocities which it consists of $n$ stationary random processes with zero means ${ }^{[8]}$ :

$$
\begin{gathered}
V_{j}(t)=\sum_{k=1}^{j} \sum_{j=1}^{N}\left|H_{\mathrm{jm}}\left(\omega_{l}\right)\right| * \sqrt{2 \Delta \omega} \cos \omega_{l} * t+\varphi_{j m}(t) \\
+\theta_{m l} \underset{\mathrm{j}=1,2, \cdots, \mathrm{n}}{ }
\end{gathered}
$$


In formula (4), $N$ is a sufficiently large positive number, $\Delta \omega=\left(\omega_{b}-\omega_{a}\right) / N$ is Frequency division, $\omega_{k}=$ $(k-1) * \Delta \omega, \quad \varphi_{\mathrm{kl}}$ is a random number with an intermediate mean distribution between 0 and 2 $\pi, \theta_{\mathrm{jk}}\left(\omega_{l}\right)=\arctan \frac{i m\left(H_{j k}\left(\omega_{l}\right)\right)}{r e\left(H_{j k}\left(\omega_{l}\right)\right)}$.

Have adopted Davenport fluctuating wind speed power spectrum and simulated the wind speed time history curves of each node by programmed with Matlab software to get wind speed-time history data, See table 3 for specific parameters. Figure 6 shows the wind speed time-history curve of node 472.

Wind load is calculated from the wind speed using the following formula, Figure 7 shows the wind load time history of 472 .

$$
\mathrm{F}=\mu_{z i} \frac{V_{i}^{2}}{1600} A_{i}(K N)
$$

In formula(6), $\mathrm{V}$ is the average sum of wind and fluctuating $\operatorname{wind}(\mathrm{m} / \mathrm{s}) \cdot \mu_{z i}$ is the wind pressure height coefficient, $A_{i}$ is the $\operatorname{area}\left(\mathrm{m}^{2}\right)$

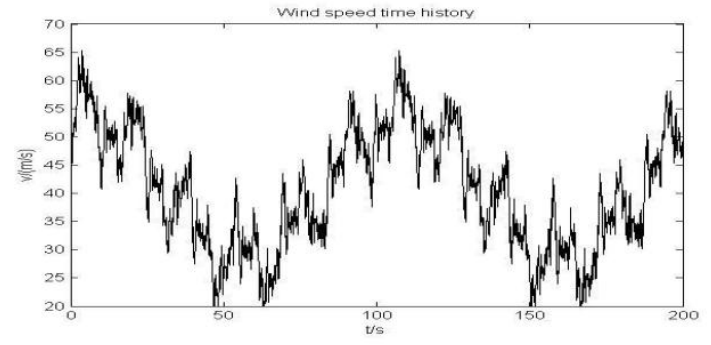

Fig.6. Simulated wind velocity time-history

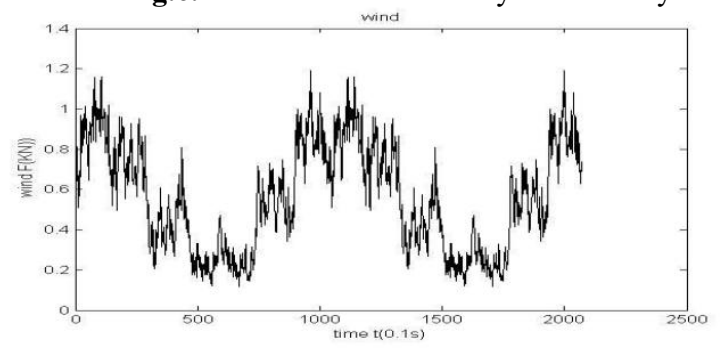

Fig.7. Wind load time history of node 472

\subsection{Wind vibration response}

The largest displacement in the center of the platform of the climbing formwork under wind load, Figure 8 shows the displacement time history, we can see that the maximum value is $15.3 \mathrm{~mm}$.

Due to the poor bending resistance of the structure, the rod is prone to bending with the wind load. Figure 9 shows that the maximum displacement difference between node 150 and node 161 , which reach $70.42 \mathrm{~mm}$

Table 3. Simulation parameters

\begin{tabular}{|c|c|}
\hline Category & Value \\
\hline Basic wind velocity & $28.28 \mathrm{~m} / \mathrm{s}$ \\
\hline Sampling number & 2048 \\
\hline Interval & $0.1 \mathrm{~s}$ \\
\hline Simulation time & $204.8 \mathrm{~s}$ \\
\hline Roughness coefficient & 0.16 \\
\hline
\end{tabular}

\begin{tabular}{|c|c|}
\hline Topography & B \\
\hline Height & $100 \mathrm{~m}$ \\
\hline
\end{tabular}

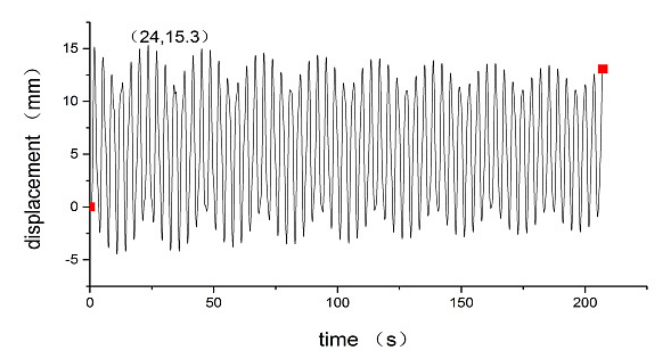

Fig. 8. Displacement time-history response of node 472

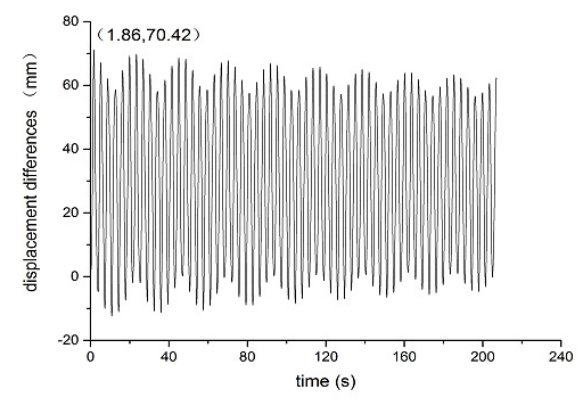

Fig. 9. The displacement difference

\section{Conclusion}

In order to study the wind-induced vibration characteristics of hydraulic climbing formwork at high altitude under the wind load, Davenport wind speed spectrum was used to simulate the time-history of wind load at $100 \mathrm{~m}$ in MATLAB, and ANSYS finite element software was used to calculate the wind vibration response of the climbing formwork under forward wind, got the following conclusion:

1.This paper studies the method of calculating the wind load, improve the anti-wind design method of the climbing formwork.

2.The first mode show the rotation along the $\mathrm{z}$ axis, which is manifested as the vibration of the lower platform. Workers should pay attention to safety when working on the lower platform.

3.It is clearly to see the bending when the climbing formwork working at high altitude, which the difference between the upper and lower ends can reach $70.42 \mathrm{~mm}$ 。

\section{References}

1. Liu. R, X. Tong, On the construction technology of hydraulic sliding formwork. J. New Technology \& New Products of China,14,194(2009)

2. M. Ramesh, M. Kannan, M. Helen Santhi. Constructability assessment of climbing formwork systems using building information modelling. J .Procedia eengineering,64,1129(2013) 
3. Long. Q, G. Zhang, Construction and application of hydraulic clamping system.Journal of Chongqing Jiao tong University, 25(3),26(2006)

4. He. Y, M, Profile of Shanghai Jiao Tong University Press, .2012

5. Liu. X.L,Y. Zhou. J. Industrial construction .35(5),81(2015)

6. Deodatis G, Simulation of ergodic multivariate stochastic processes. J .Engng Mech ASCE.1996

7. Wang. Z.H, Simulation of wind load.J.Journal of building structures, 15,44(1994)

8. Liu. L.W, J.Y. Sui, Simulation of pulsating wind load in high-rise structures. J. Proceedings of the 16 th national conference on structural engineering, 3,90(2007) 